\title{
Improvement on the production of high-performance bone char
}

\author{
H. Li, W. Jiang, Y. Huang, Z. Li \& W. Qi \\ Sichuan University, China
}

\begin{abstract}
Bone char is widely used in sewage disposal and drinking water purification. However, in many cases, the existing method of industrial production of bone char cannot create the maximum adsorbability of the bone char. It's a big problem which is waiting to be solved.

According to classification experiments, we explored the adsorbability of bone char under the circumstances of different temperatures and calcination times. Finally, we found the best temperature and calcination time approximately, which is significant for the industry production.

Keywords: high-performance bone char, temperature, calcination time.
\end{abstract}

\section{Introduction}

Bone char is produced from the animal bone, which is mainly made up of hydroxyapatite $\left(\mathrm{Ca}_{5}\left(\mathrm{PO}_{4}\right)_{3}(\mathrm{OH})\right)$ [1]. It is widely used in the field of sewage disposal and drinking water purification. It also is used in the adsorption of fluoride [2], lead [3], and arsenic [4]. The mechanism is considered to be the exchange of the ionic groups between the oxhydryl of hydroxyapatite and the removed ion [5].

According to the existing method of industrial production, bone char is usually produced by high-temperature calcination. However, the best temperature and the best time of termination are not certain. It's evident that the solution of this problem may improve the quality of the bone char and improve the efficiency of industrial production at the same time. 


\section{Materials and methods}

We chose bovine bone as the raw material because the internal structure of the bovine bone is more porous than any other animal bone. It's more suitable to be treated as the adsorbent. On the basis of the major method of bone char producing, we first calcined 30 gram of raw materials under the temperature of 1400 degree Celsius (general production temperature). Thirty minutes later, the exterior of raw materials had turned from black to gray. Then we took out the material, and cooled it down at room temperature. Then, the efficiency of the bone char we made was tested compared with the bone char on the market. To show the adsorption capacity of the two kinds of bone char, we used the chloride solution $(0.5 \mathrm{~mol} / \mathrm{L}, 10 \mathrm{~mL})$ as the sample. Through five minutes' sufficiently stirred, we checked the concentration of the two samples (sample 1 is the sample used the bone char we made; sample 2 is the sample used the bone char from the market).

Table 1: $\quad$ The adsorptive situations of the two samples.

\begin{tabular}{|c|c|c|c|c|c|}
\hline $\begin{array}{c}\text { times } \\
\text { sample }\end{array}$ & $1(\mathrm{~mol} / \mathrm{L})$ & $2(\mathrm{~mol} / \mathrm{L})$ & $3(\mathrm{~mol} / \mathrm{L})$ & $4(\mathrm{~mol} / \mathrm{L})$ & $5(\mathrm{~mol} / \mathrm{L})$ \\
\hline $\begin{array}{c}\text { sample } \\
1\end{array}$ & 0.37 & 0.39 & 0.33 & 0.37 & 0.38 \\
\hline $\begin{array}{c}\text { sample } \\
2\end{array}$ & 0.12 & 0.14 & 0.15 & 0.11 & 0.14 \\
\hline
\end{tabular}

We plotted the curve graph of these data as shown in Figure 1.

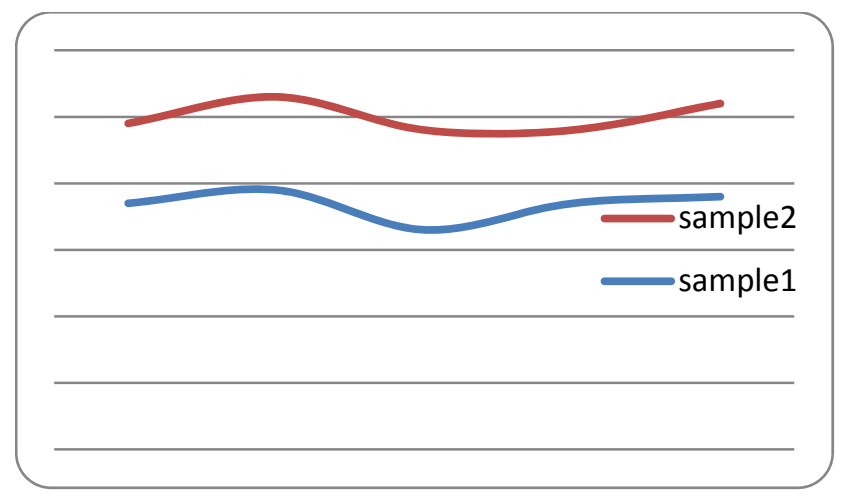

Figure 1: The adsorptive situations of the two sample. 
We can draw a conclusion from the chart that though there is a difference between the two kinds of bone char, but the difference value of the efficiency is approximate constant. Therefore, we can regard the bone char we made had the same trend as those from the market. Hence we can do the following experience as we designed:
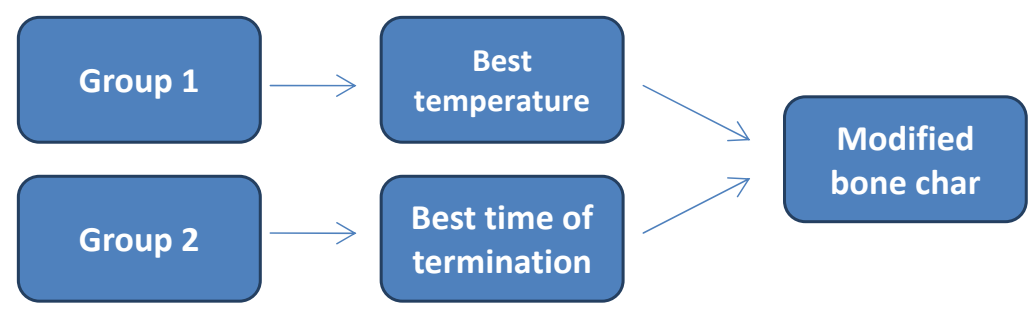

Figure 2: $\quad$ The method of the experiment.

To determine the suitable temperature of the procedure of bone char production, we used the method of bisection to finish the experiment. Firstly, we divided the experiment group 1 into ten groups(A-J), each group represented a confirmed temperature: A- $200^{\circ} \mathrm{C}, \mathrm{B}-400^{\circ} \mathrm{C}, \mathrm{C}-600^{\circ} \mathrm{C}, \mathrm{D}-800^{\circ} \mathrm{C}, \mathrm{E}-1000^{\circ} \mathrm{C}, \mathrm{F}-$ $1200^{\circ} \mathrm{C}, \mathrm{G}-1400^{\circ} \mathrm{C}, \mathrm{H}-1600^{\circ} \mathrm{C}, \mathrm{I}-1800^{\circ} \mathrm{C}, \mathrm{J}-2000^{\circ} \mathrm{C}$; and each group also divided into ten groups in different times of calcination: $15 \mathrm{~min}, 20 \mathrm{~min}, 25 \mathrm{~min}, 30 \mathrm{~min}$, $35 \mathrm{~min}$, 40min, 45min, 50min, 55min, 60min. Therefore, we tested the bone char's adsorbability in the chloride solution $(0.5 \mathrm{~mol} / \mathrm{L}, 10 \mathrm{~mL})$. The data is presented as shown in Table 2 (each data of one form is the average value of several experiments in the same condition).

From the Table 2 and Figure 3, we found that the best time of Group A to C is between 25 minutes to 35 minutes; the best time of Group $\mathrm{D}$ to $\mathrm{F}$ is between 30 minutes to 40 minutes; the best time of Group $\mathrm{G}$ to $\mathrm{J}$ is between 35 minutes to 45 minutes. Comparing with each group, we found that Group F had the best adsorptivity and the best time for calcination is between 30 minutes to 40 minutes. And the adsorptivity is much better than the bone char from the market.

Table 2: $\quad$ The adsorptive test.

\begin{tabular}{|c|l|l|l|l|l|l|l|l|l|l|}
\hline $\begin{array}{c}\text { time } \\
\text { Type }\end{array}$ & $\begin{array}{c}15 \\
\mathrm{~mol} / \mathrm{L}\end{array}$ & $\begin{array}{c}20 \\
\mathrm{~mol} / \mathrm{L}\end{array}$ & $\begin{array}{c}25 \\
\mathrm{~mol} / \mathrm{L}\end{array}$ & $\begin{array}{c}30 \\
\mathrm{~mol} / \mathrm{L}\end{array}$ & $\begin{array}{c}35 \\
\mathrm{~mol} / \mathrm{L}\end{array}$ & $\begin{array}{c}40 \\
\mathrm{~mol} / \mathrm{L}\end{array}$ & $\begin{array}{c}45 \\
\mathrm{~mol} / \mathrm{L}\end{array}$ & $\begin{array}{c}50 \\
\mathrm{~mol} / \mathrm{L}\end{array}$ & $\begin{array}{c}55 \\
\mathrm{~mol} / \mathrm{L}\end{array}$ & $\begin{array}{c}60 \\
\mathrm{~mol} / \mathrm{L}\end{array}$ \\
\hline $\mathrm{A}$ & 0.44 & 0.41 & 0.37 & 0.33 & 0.38 & 0.41 & 0.44 & 0.48 & 0.49 & 0.49 \\
\hline $\mathrm{B}$ & 0.48 & 0.33 & 0.31 & 0.27 & 0.33 & 0.34 & 0.41 & 0.43 & 0.44 & 0.48 \\
\hline $\mathrm{C}$ & 0.49 & 0.36 & 0.33 & 0.21 & 0.22 & 0.24 & 0.31 & 0.37 & 0.41 & 0.48 \\
\hline $\mathrm{D}$ & 0.46 & 0.37 & 0.33 & 0.24 & 0.15 & 0.19 & 0.22 & 0.28 & 0.33 & 0.37 \\
\hline $\mathrm{E}$ & 0.41 & 0.37 & 0.29 & 0.09 & 0.07 & 0.11 & 0.13 & 0.22 & 0.23 & 0.24 \\
\hline $\mathrm{F}$ & 0.42 & 0.23 & 0.18 & 0.06 & 0.03 & 0.05 & 0.07 & 0.13 & 0.14 & 0.28 \\
\hline $\mathrm{G}$ & 0.47 & 0.28 & 0.17 & 0.13 & 0.09 & 0.08 & 0.18 & 0.32 & 0.34 & 0.39 \\
\hline $\mathrm{H}$ & 0.39 & 0.24 & 0.23 & 0.17 & 0.12 & 0.08 & 0.17 & 0.28 & 0.29 & 0.35 \\
\hline $\mathrm{I}$ & 0.44 & 0.37 & 0.33 & 0.28 & 0.17 & 0.14 & 0.19 & 0.21 & 0.24 & 0.31 \\
\hline $\mathrm{J}$ & 0.49 & 0.36 & 0.33 & 0.29 & 0.26 & 0.18 & 0.22 & 0.27 & 0.33 & 0.38 \\
\hline
\end{tabular}




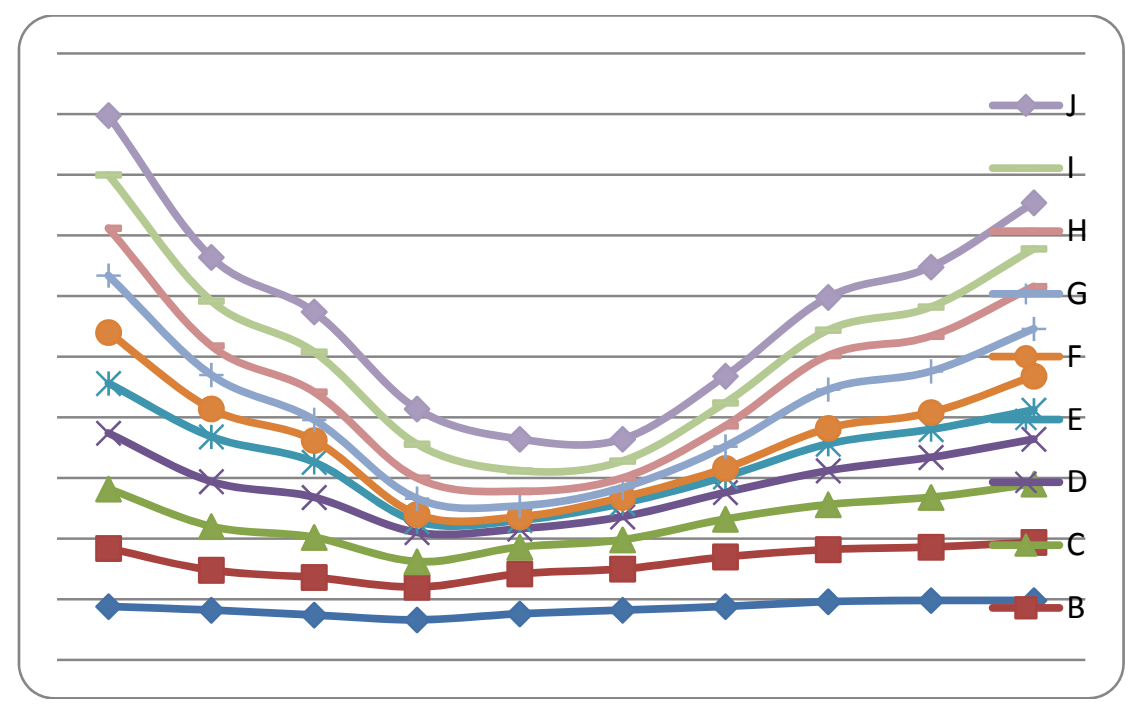

Figure 3: $\quad$ The adsorptive test.

We can draw a conclusion that to product the more efficient bone char, in the case of raw materials uniformly ground, we can choose the temperature of 1200 degree Celsius, and the time for calcination is approximately between 30 minutes to 40 minutes.

\section{References}

[1] Yunbo Wang, Defluoridation Effect Study of Zeolite, Bone Charcoal and Activated Alumina[J], J. Xi'an Univ. of Arch. and Tech. (Natural Science Edition), 34(4)(2002):325-327.

[2] Ding Wang, The Research in Bone Char Powder Used for Drinking Water Fluoride[J], Water Resource Protection, 24(1)(2008):63-65.

[3] Man Teng, The Research in Bone Char's adsorbability of lead[J], Environmental Science and Technology, 33(3)(2010):87-91.

[4] Yunnen Chen, The Research in Bone Char's adsorbability of arsenic[J], J. Cent. South Univ. (Science and Technology), 39(2) (2008):281-283.

[5] Yong Wang, Research on removing fluoride mechanism from drinking water by using bone char[J], Journal of Guangzhou University (Natural Science Edition), 2(5)(2003):423-426. 